\title{
Integração do SWMM e ferramentas SIG para modelagem hidrológico-hidráulica de bacia complexa
}

\author{
SWMM and GIS tools integration for hydrological-hydraulic \\ modeling of a complex basin
}

\author{
Maria de Jesus Delmiro Rocha', Silvano Porto Pereira ${ }^{1,2}$, Iran Eduardo Lima Neto"*
}

\section{RESUMO}

O presente trabalho aplicou o Storm Water Management Model (SWMM) para simular e avaliar a resposta hidrológica do sistema de macrodrenagem de um rio costeiro, cuja bacia situa-se em área de transição urbano-rural e apresenta influência marítima em seu exutório. Assim, como condição de contorno de jusante, reconstruiu-se a curva de maré existente no exutório da bacia por meio do método harmônico. Ademais, realizou-se a delimitação dos trechos de escoamento e a discretização das sub-bacias automaticamente e desenvolveuse um mapa de uso e ocupação do solo para obtenção dos parâmetros físicos e espaciais dos elementos da drenagem, etapas estas auxiliadas por ferramentas de Sistemas de Informações Geográficas (SIG). Procedeu-se à simulação das vazões no sistema para o período de um mês sob condição de precipitação moderada. A validação do modelo resultou em um coeficiente de NashSutcliffe de 0,57. Os resultados mostraram que o SWMM simulou as vazões nos trechos de drenagem das sub-bacias rurais com desvio médio de 8,6\% das vazões medidas em campo. Para os trechos sob influência marinha, o SWMM conseguiu reproduzir o efeito da maré nos trechos, apresentando uma oscilação completa. Ademais, obteve-se a descarga fluvial média da bacia ao estuário de 2,35 $\mathrm{m}^{3} \mathrm{~s}^{-1}$ e a vazão média mensal afluente ao maior reservatório da bacia de $0,33 \mathrm{~m}^{3} \mathrm{~s}^{\mathrm{s}}$, resultados estes em consonância com trabalhos anteriores realizados na bacia em estudo. Em síntese, os resultados obtidos e o modelo proposto têm potencial para auxiliar na gestão integrada de águas rurais, urbanas e costeiras.

Palavras-chave: transformação chuva-vazão; macrodrenagem urbana; Sistemas de Informações Geográficas; modelo semidistribuído; influência de maré.

\begin{abstract}
The present work applied the Storm Water Management Model (SWMM) to simulate and evaluate the hydrological response of a coastal river macrodrainage system whose basin is located in an urban-rural transition area and has a tidal influence in its outflow. Thus, as a downstream contour condition, the existing tidal curve in the basin's outlet was reconstructed using the harmonic method. In addition, drainage stretches and sub-basins were automatically delimited, and a land use and occupation maps were developed to obtain the physical and spatial parameters of the drainage elements, these steps being aided by Geographic Information Systems (GIS) tools. The flow was simulated in the system for a period of one month under a moderate precipitation condition. The validation of the model resulted in a Nash-Sutcliffe coefficient of 0.57. The results showed that the SWMM simulated the flows in the drainage stretches of the rural sub-basins with an average deviation of $8.6 \%$ of the flows measured in the field. For stretches under tidal influence, SWMM was able to reproduce the effect of the tide in the stretches with a complete oscillation. In addition, the river discharge from the basin to the estuary was $2.35 \mathrm{~m}^{3} \cdot \mathrm{s}^{-1}$, on average, and the average monthly flow affluent to the largest reservoir in the basin was $0.33 \mathrm{~m}^{3} . \mathrm{s}^{-1}$, consistently with previous work carried out in the study basin. In summary, the results obtained and the proposed model have the potential to assist in the integrated management of rural, urban, and coastal waters.
\end{abstract}

Keywords: rainfall-runoff transformation; urban macro-drainage; Geographic Information Systems; semi-distributed model; tidal effect.

\section{INTRODUÇÃO}

As ações antrópicas em bacias urbanas, principalmente os processos de impermeabilização e intervenções na macrodrenagem, modificam significativamente o volume e o comportamento da água escoada (CARDOSO et al., 2014). Devido aos custos associados aos sistemas de drenagem, sua dinâmica

de funcionamento e o estresse associado as suas falhas, faz-se necessária a antecipação desses desafios (BABOVIC; MIJIC; MADANI, 2018). A modelagem da propagação do escoamento na drenagem urbana constitui-se como uma ferramenta estratégica para planejamento operacional da bacia, gerenciamento de riscos e falhas nos sistemas (GIRÃO et al., 2017), análise de interação entre

'Universidade Federal do Ceará - Fortaleza (CE), Brasil.

${ }^{2}$ Companhia de Água e Esgoto do Ceará - Fortaleza (CE), Brasil.

*Autor correspondente: iran@ufc.br

Conflitos de interesse: os autores declaram não haver conflito de interesses.

Financiamento: Coordenação de Aperfeiçoamento de Pessoal de Nível Superior (Capes)/Programa de Excelência Acadêmica (Proex).

Recebido: 13/10/2O19 - Aceito: 18/04/2O2O - Reg. ABES: 20190328 
as sub-bacias (MAKSIMOVIC et al., 2009) e avaliação do desempenho do sistema (CAMPOS; RABELO; LIMA NETO, 2020) e do transporte de poluentes (MESQUITA; PEREIRA; LIMA NETO, 2020).

Dada essa elevada importância, diversos modelos hidrológicos e hirodinâmicos são aplicados visando fundamentar a análise e a interpretação do fenômeno de escoamento através da transformação chuva-vazão, mediante a complexidade e a quantidade de variáveis envolvidas nesse processo. O software Storm Water Management Model (SWMM), desenvolvido pela US Environmental Protection Agency (EPA), consiste em um modelo de simulação chuva-vazão amplamente utilizado para a modelagem hidrológica urbana, seja através de eventos pontuais ou de séries de precipitação (BARCO; WONG; STENSTROM, 2008; VINAGRE; LIMA; LIMA JÚNIOR, 2015; FORMIGA et al., 2016; KONG et al., 2017). A utilização do SWMM, porém, demanda caracterização física e espacial acurada das sub-bacias, principalmente quanto aos parâmetros de uso e ocupação do solo (NIEMI et al., 2019). Ainda assim, a aplicação de modelos distribuídos, capazes de capturar essas heterogeneidades nas características das bacias, configura-se em uma melhor representação dos mecanismos físicos da realidade (NGUYEN et al., 2016).

Entretanto, ainda que o SWMM tenha sido extensamente aplicado em estudos anteriores para modelagem dos sistemas de drenagem, estes abrangeram principalmente a simulação da microdrenagem ou de pequenas bacias densamente urbanizadas (KREBS et al., 2013; GIRÃO et al., 2017; BATISTA; BOLDRIN, 2018). A aplicação do SWMM para a modelagem do sistema de macrodrenagem de um rio costeiro, com uma bacia de larga escala e características transitórias urbano-rural em sua ocupação, configura-se como ferramenta potencial para avaliação das vazões produzidas em trechos de áreas urbanas que possuem uma região periférica em processo de transição, situação esta comum à maioria das cidades litorâneas do Nordeste brasileiro (MIRANDA; GOMESJÚNIOR, 2017; BEZERRA; SILVA, 2018).

Assim, o presente estudo objetiva avaliar e validar a aplicabilidade do SWWM para reprodução das vazões em um sistema de macrodrenagem complexo, com bacia hidrográfica em área de transição urbano-rural e influência marítima em seu exutório. Para tanto, utiliza-se o software com ferramentas baseadas em Sistemas de Informações Geográficas (SIG) para simulação hidrológico-hidráulica do sistema de macrodreangem da bacia do rio Cocó, no Estado do Ceará, Brasil. Desse modo, espera-se produzir avanços cientíticos quanto ao processo de transformação chuva-vazão em bacias hidrográficas heterogêneas, bem como fornecer ferramentas que possam auxiliar na gestão integrada das águas.

\section{METODOLOGIA}

\section{Área em estudo}

A área de estudo consiste na bacia hidrográfica do rio Cocó, abrangendo parte dos municípios de Fortaleza, Eusébio, Maracanaú, Pacatuba e Itaitinga, localizados no Estado do Ceará, Nordeste do Brasil, com uma área total aproximada de $485 \mathrm{~km}^{2}$. O principal rio da área em estudo, o rio Cocó, devido à extensão da sua bacia hidrográfica, percorre zonas rurais e urbanas além de incidir sobre a zona costeira de Fortaleza. É considerado o principal recurso hídrico da capital cearense, com uma extensão total de $50 \mathrm{~km}$, atravessando 18 bairros da cidade e sendo responsável por cerca de $60 \%$ de toda a drenagem do município (COGERH, 2010). A Figura 1 apresenta a localização da área em estudo.
A bacia estudada apresenta sua maior densidade urbana em Fortaleza. Nos demais municípios que abrange, a maior densidade residencial e populacional localiza-se em suas sedes urbanas, restando a maior parte de seus territórios com população rural dispersa e cobertura vegetal remanescente ou áreas antropizadas. Desse modo, prosseguiu-se a uma classificação da bacia a partir de suas sub-bacias delimitadas, dividindo-as majoritariamente em duas macrocategorias: sub-bacias rurais e sub-bacias urbanas. Adotou-se como indicador o percentual de impermeabilidade das sub-bacias para proceder a essa subdivisão.

\section{Delimitação das sub-bacias}

A primeira etapa para a delimitação das sub-bacias consiste na obtenção de um modelo digital de terreno em que seja possível extrair seus principais parâmetros físicos: área de drenagem $(\mathrm{A})$, largura característica $(\mathrm{W})$, declividade média (D) e cota de fundo dos nós e exutório (R).

A qualidade do modelo utilizado, especialmente sua resolução espacial, impacta diretamente na delimitação da drenagem natural. Sendo a bacia em estudo majoritariamente urbana e composta de pequenos riachos e tributários, quanto melhor for a resolução espacial do modelo digital de elevação (MDE) utilizado, mais precisa e completa será a drenagem delimitada (SANDWELL et al., 2008). No presente trabalho, utilizou-se um modelo digital de superfície (MDS) absoluto gerado a partir de cenas do satélite ALOS, sensor PALSAR, modo FBS, com resolução espacial de $12,5 \mathrm{~m}$, radiometricamente corrigido no solo e disponibilizado pelo departamento de Processamento de Dados Alaska Satelite Facility. Foram utilizados dois MDS's para cobrir toda a área em estudo, os quais foram pré-processados no software $\mathrm{ArcGIS}^{\oplus}$ para preenchimento de possíveis falhas, unidos para formação de um mosaico, reduzidos à área necessária e reprojetados para o sistema de coordenadas SIRGAS 2000 UTM ZONE 24 SOUTH.

Para a delimitação automática do sistema de drenagem e das sub-bacias, utilizou-se o software Better Assessment Science Integrating Point and Nonponit Sources (BASINS), desenvolvido pela EPA. Nessa etapa, foram necessários os parâmetros: grau de detalhamento da delimitação para o método dos limiares, o

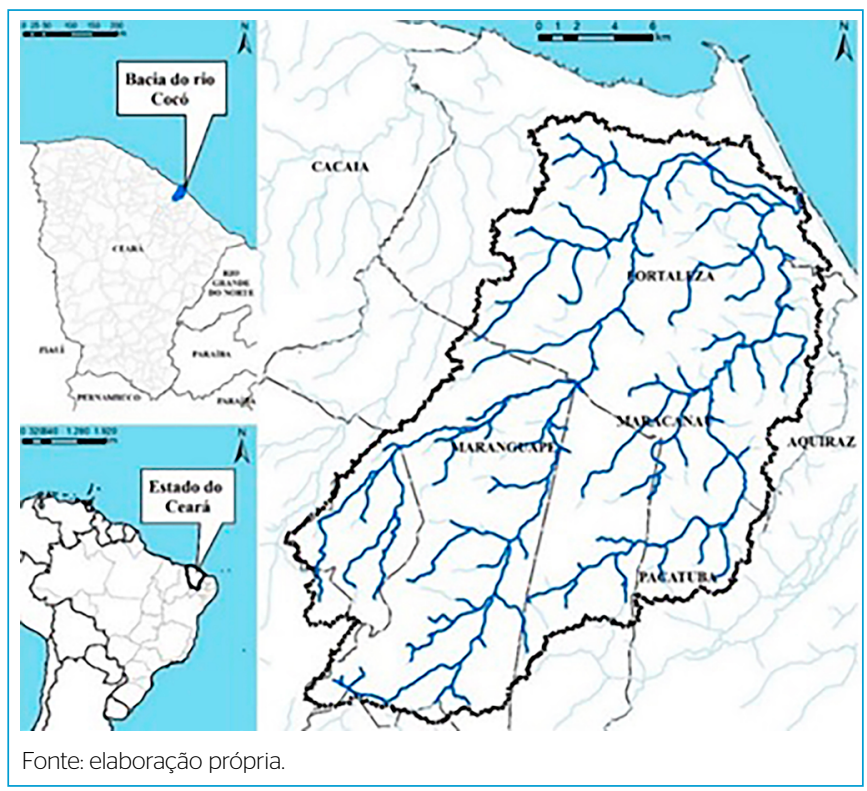

Figura 1 - Localização da bacia hidrográfica do rio Cocó, no Estado do Ceará, Brasil. 
threshold, e a linha de drenagem basilar. Este último é necessário para melhorar a qualidade dos trechos delimitados uma vez que se utilizou um MDS. Para o threshold, adotou-se o valor de 0,3\%, e para a linha basilar, a drenagem levantada pela Agência Nacional de Águas (ANA) na Base Hidrográfica Ottocodificada das Bacias Hidrográficas do Atlântico Nordeste Oriental. Para a delimitação automática da drenagem e o traçado das sub-bacias pelo BASINS, utilizou-se o algoritmo D8.

\section{Dados meteorológicos}

Para a realização das simulações com o modelo chuva-vazão do SWMM, necessita-se da precipitação como condição inicial para a geração de fluxo. Com o intuito de minimizar erros de continuidade de fluxo, a discretização temporal ideal dessa precipitação é em intervalos de um a cinco minutos, segundo o manual do software.

Os dados de precipitação disponíveis constam no volume precipitado em intervalos de cinco minutos, coletados na estação meteorológica do Pici, Fortaleza, Ceará, para o mês de agosto de 1996. A utilização dessa estação, ainda que não localizada exatamente dentro da bacia, deve-se à disponibilidade dos dados de chuva referentes ao período das medições discretizados no passo de tempo demandado pelo SWMM. De todo modo, com vistas a verificar a representatividade da série de precipitação usada, levantou-se todos os postos pluviométricos monitorados dentro da bacia e com dados para o período desejado, uma vez que não há postos pluviográficos disponíveis na região. Avaliou-se, então, o desvio médio percentual da precipitação total para o mês de agosto de cada posto em relação ao posto do Pici e a proximidade da distribuição temporal diária de cada um com o posto usado.

\section{Classificação do uso e ocupação do solo}

A descrição do uso e ocupação do solo da bacia é de fundamental relevância uma vez que se adotou o modelo de infiltração Curva-Número. Para se obter os parâmetros relativos à permeabilidade das sub-bacias, é necessário um mapa de uso e ocupação do solo da região. Realizou-se então a classificação supervisionada do solo na bacia com a cena S2B_MSIL1C de 18 julho de 2018 do satélite Sentinel-2B com $10 \mathrm{~m}$ de resolução espacial. Foram considerados os seguintes tipos de usos do solo: vegetação de baixa densidade, telhado e cobertas, rua pavimentada com meio fio e drenagem, rua em cascalho e solo exposto, dunas, oceano e água, além da adição do maior reservatório da bacia, o Gavião, como unidade de armazenamento separada no modelo. Deve-se ressaltar que os usos do solo adotados seguiram, com necessárias adequações, os usos propostos pelo manual do SWMM.

A Figura 2 mostra as sub-bacias e a macrodrenagem delimitadas, destacando os principais trechos para o presente trabalho utilizados para calibração e validação das vazões modeladas. Apresenta-se o total de 173 sub-bacias, 549 condutos e 586 nós. Observa-se ainda na Figura 2 o uso do solo classificado para toda a região, os pluviômetros existentes na bacia, bem como o pluviômetro do Pici, usado para as simulações.

Contudo, objetivando avaliar a mudança nas condições de uso e ocupação do solo entre o período de medição das vazões e o período de 2018, foram realizadas duas classificações supervisionadas de uso do solo complementares para comparação das mudanças ocorridas por tipo de uso e por sub-bacia. Para esse fim, foram utilizadas imagens dos satélites Landsat 4 , em meados de julho de 1996, e Landsat 8, no início de agosto de 2017. Optou-se pelo ano de $2017 \mathrm{em}$ razão da elevada nebulosidade em todas as imagens disponíveis pelo respectivo satélite para o mesmo período em 2018, obstaculizando assim a realização da classificação. Ademais, a escolha do satélite Landsat deu-se principalmente pela disponibilização gratuita das imagens de melhor resolução para o ano de 1996. Por fim, utilizar o mesmo satélite e a mesma resolução espacial para ambas as datas favorece a diminuição de erros no processo de comparação.

\section{Parametrização das sub-bacias}

Adotou-se o modelo de infiltração Curva-Número do Soil Conservation Service, sendo então necessário obter o parâmetro Curve Number $(\mathrm{CN})$ para cada sub-bacia. Considerou-se classe II para umidade antecedente do solo, após verificação da precipitação antecedente na área de interesse disponível em Funceme (2019). Com o mapa de uso e ocupação do solo construído, adotou-se a classe hidrológica dos solos e o CN do National Research Conservation Service (NRCS) conforme apresentado na Tabela 1. O CN de cada sub-bacia foi calculado através da média ponderada do $\mathrm{CN}$ de cada categoria de uso e respectiva área na sub-bacia.

Ademais, para cada sub-bacia é necessário obter os parâmetros: percentual de impermeabilidade (PcntImperv), coeficiente de rugosidade de Manning para área impermeável (N_Imperv) e para área permeável (N_perv), profundidade do armazenamento em depressão para área permeável (S_Perv) e para área impermeável (S_Imperv), e percentual da área impermeável sem armazenamento em depressão (PcntZero). Para a drenagem, é necessário obter o coeficiente de rugosidade de Manning em cada trecho.

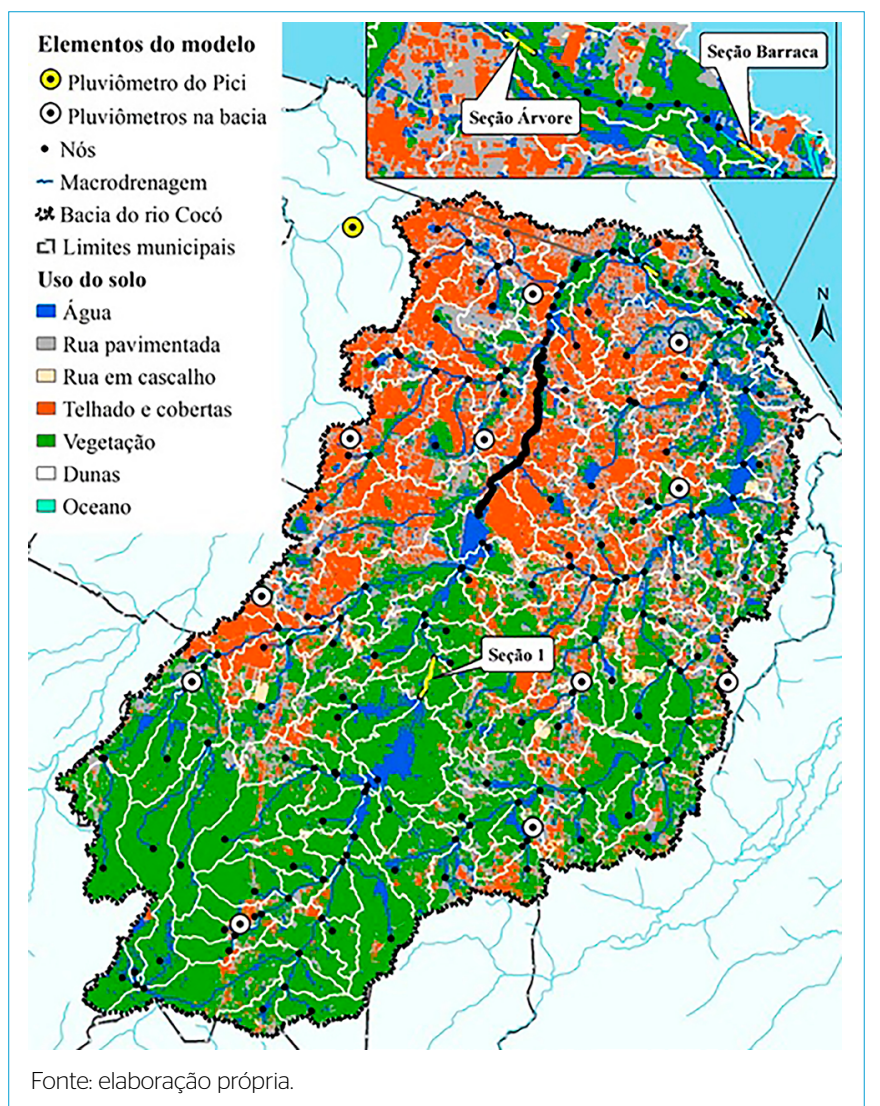

Figura 2 - Elementos do sistema de macrodrenagem com destaque às seções de controle para calibração e validação junto aos pluviômetros e o mapa de uso e ocupação do solo na área em estudo. 
O percentual de impermeabilidade para cada sub-bacia foi determinado da seguinte forma:

- caracterização do uso e cobertura do solo da bacia conforme já descrito;

- determinação de um percentual de impermeabilidade para cada tipo de uso do solo, de acordo com o manual do SWMM;

- cálculo do percentual de impermeabilização através da média ponderada dos coeficientes de todas as categorias de uso e a área do respectivo uso do solo por sub-bacia.

O coeficiente de rugosidade de Manning representativo para as áreas permeáveis e impermeáveis de cada sub-bacia foi obtido de acordo com a Equação 1, em que para obter o coeficiente de Manning médio para a superfície permeável substitui-se o percentual de impermeabilidade pelo percentual de permeabilidade.

$\mathrm{N}_{\text {Imperv }_{\mathrm{Sj}}}=\frac{\sum_{\mathrm{i}=1}^{7}\left[\operatorname{Pcnt}_{\text {Imperv }_{\mathrm{i}}} * \mathrm{~A}_{\mathrm{i}} * \mathrm{~N}_{\mathrm{i}}\right]}{\sum_{\mathrm{i}=1}^{7}\left[\operatorname{Pcnt}_{\text {Imperv }_{\mathrm{i}}} * \mathrm{~A}_{\mathrm{i}}\right]}$

Em que:

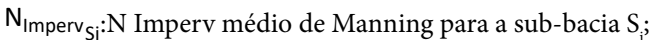

Pcnt Impervi: Pcnt Imperv do uso do solo $i$;

$\mathrm{A}_{\mathrm{i}}$ : Área de uso do solo $i$ na sub-bacia $\mathrm{S}_{j}$;

$\mathrm{N}_{\mathrm{i}}: \mathrm{N}$ de Manning para o uso do solo $i$;

$\sum_{i=1}^{7}\left[\right.$ Pcnt $\left._{\text {mpeer }}{ }^{*} A_{i}\right]$ : Área total impermeável da sub-bacia $S_{j}$;

O valor do coeficiente de rugosidade de Manning para cada tipo de uso do solo adotado e usado como variável na Equação 1 foi:

- água e oceano: 0;

- rua pavimentada: 0,011 ;

- solo exposto: 0,020;

- telhado e laje: 0,0150 ;

- vegetação: 0,1500;

- dunas: 0,1300 .

Quanto aos parâmetros S_Perv e S_Imerv, tomou-se um valor médio ponderado pela área de cada uso para cada sub-bacia conforme sugerido pelo manual do SWMM, sendo para o solo exposto e dunas considerado o valor referente a gramado; para vegetação, o valor de pastagem; e para rua pavimentada, água e oceano, o valor médio para superfícies impermeáveis, sugeridos pelo mesmo manual. Por fim, para o parâmetro PcntZero, foi empregado o percentual de $25 \%$, de acordo com Gironás, Roesner e Davis (2009), para casos em que não há informações suficientes.

\section{Parametrização dos condutos}

Para o valor inicial do coeficiente de rugosidade de Manning para os trechos da drenagem, avaliou-se a superposição dos arquivos vetoriais da drenagem natural delimitada com a drenagem artificial obtida da prefeitura de Fortaleza. Para os trechos onde havia superposição, adotou-se coeficiente de Manning para canais abertos de concreto, e para os demais trechos, adotou-se o valor do coeficiente para canais naturais de seção irregular, ambos segundo o manual do SWMM.

Ademais, foram inseridas as seções transversais ao longo da zona estuarina do rio Cocó obtidas por levantamento topográfico para o ano de 2017 e disponibilizadas para a Companhia de Água e Esgoto do Ceará (Cagece). As seções levantadas partem da foz do rio, nos trechos sob influência marítima, com distanciamento variando entre 400 e $600 \mathrm{~m}$, totalizando 29 seções.

Por fim, ao trecho localizado imediatamente a jusante do reservatório Gavião, Seção 1, foram adicionados uma vazão-base e o padrão temporal mensal para o lançamento dessa vazão permanente referente à água de lavagem dos filtros da Estação de Tratamento de Água Gavião, operada pela Cagece. O padrão temporal foi obtido a partir dos dados de vazão tomando-se a razão entre a vazão média anual e a vazão no respectivo mês. A vazão-base, por usa vez, refere-se à média das vazões lançadas pela ETA de, aproximadamente, $0,34 \mathrm{~m}^{3} \cdot \mathrm{s}^{-1}$.

\section{Condições de contorno para simulação}

A zona estuarina do rio Cocó adentra sob influência da maré em uma extensão total a partir da sua foz de, aproximadamente, 10 km (NÓBREGA, 1998). Assim, ressalta-se a relevância da inclusão dos efeitos da maré na modelagem apropriada do escoamento nesses trechos do rio. Então, para a simulação, definiu-se o nó da foz do rio como influenciado pela maré e adicionou-se uma curva de maré para o mês de agosto de 1996 reconstruída a partir das constantes de maré extraídas dos dados monitorados pelo marégrafo instalado no porto do Mucuripe, Fortaleza, Brasil, segundo metodologia abordada por Pereira et al. (2015).

\section{Calibração do módulo runoff, simulação e validação}

O coeficiente de rugosidade de Manning para os condutos é um dos principais parâmetros de calibração no SWMM (KREBS et al., 2013). Procedeu-se então a sua calibração manual, realizada trecho a trecho, tendo sido os valores de referência para este coeficiente tomados a partir das sugestões de Chow (1973), que apresenta uma série de fotos de canais e rios rotuladas com o valor de $n$ de Manning correspondente àquelas condições. $\mathrm{O}$ ajuste manual é realizado por tentativa e erro, em repetidas execuções do modelo e análises dos resultados. A cada tentativa observa-se o ajuste de vazões mínimas, a forma do hidrograma calculado, o ajuste dos picos de cheias em termos de valor máximo, volume, forma e tempo de ocorrência.

Devido à inexistência de medição contínua de vazão na área de estudo, adotou-se para verificar o ajuste dos parâmetros do modelo uma única seção de controle próximo à foz da bacia denominada Seção Barraca, no qual os resultados obtidos para cada ajuste dos parâmetros e execução da simulação buscaram otimizar as funções objetivo coeficiente de Nash-Sutcliffe e a relação entre as vazões calculadas e observadas.

Tabela 1 - Cobertura do solo adotada para a bacia com respectivas classes hidrológicas e Curve Number conforme National Research Conservation Service.

\begin{tabular}{l|c|c|c|c|c|c|c}
\hline Uso do solo & Vegetação & Telhado e laje & Rua pavimentada & Solo exposto & Água & Oceano \\
\hline Classes & C & D & D & A & D & A & 76 \\
\hline CN & 77 & 98 & 98 & 100 & 25 \\
\hline
\end{tabular}

CN: Curve Number

Fonte: elaboração própria 
Visando à validação do modelo, foi simulado o escoamento na bacia para o período de agosto de 1996, do qual dispõe-se de dados medidos por Nóbrega (1998). A validação da simulação foi realizada buscando maximizar o coeficiente de Nash-Sutcliffe e minimizar o desvio médio entre as vazões modeladas e observadas para dois trechos ao longo do rio Cocó. Um dos trechos localiza-se a jusante do reservatório Gavião, denominado Seção 1, na porção mais rural da bacia e o outro, denominado Seção Árvore, próximo à foz e sob influência marítima, na região mais urbanizada.

\section{RESULTADOS E DISCUSSÃO}

Apresenta-se, na Figura 3, uma síntese das mudanças ocorridas para cada tipo de uso do solo na bacia estudada. Observam-se mudanças médias em torno de $10 \%$ para os usos telhados e lajes, água e solo exposto, e de $20 \%$ para rua pavimentada e vegetação, destacando-se apenas no uso vegetação a existência de algumas sub-bacias com mudanças próximas de $30 \%$. Essas mudanças mais significativas ocorreram principalmente na região da construção de um novo reservatório na bacia, havendo a substituição total do uso vegetação por água. Algumas outras bacias pontuais sofreram mudanças mais drásticas no uso, despontando-se como outliers na Figura 3.

Para grandes bacias, como a bacia em estudo, com área em torno de $500 \mathrm{~km}^{2}$ ou superior, a mudança localizada nas características da vegetação promove menores impactos na resposta hidrológica em comparação à variabilidade da precipitação (BLÖSCHL et al., 2007; RODRIGUEZ; TOMASELLA; LINHARES, 2010), ocorrendo, entretanto, maior probabilidade de influenciar preferencialmente as vazões extremas (LEI; ZHU, 2018). Contudo, a mudança

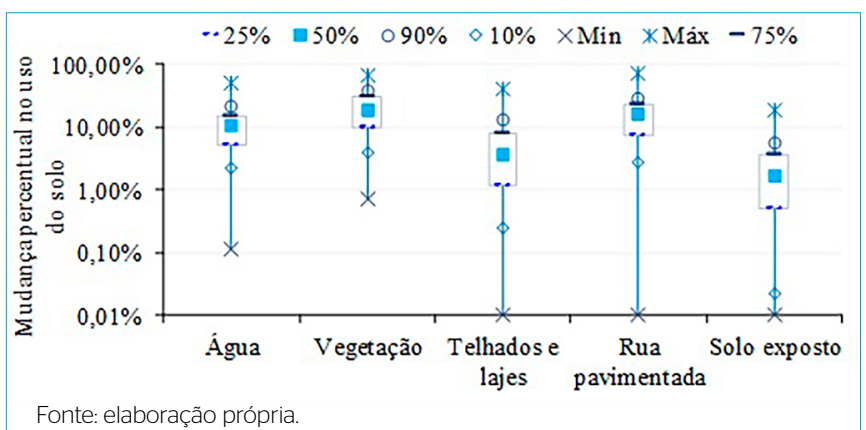

Figura 3 - Mudança ocorrida no uso e ocupação do solo da bacia do rio Cocó nos últimos 20 anos. na vegetação com taxas médias inferiores a $20 \%$ resulta em baixa influência nas vazões produzidas (BOSCH; HEWLETT, 1982). Assim, esta análise possibilita adotar a hipótese de que as vazões medidas em 1996 ainda são representativas para o rio Cocó em condições atuais.

A Tabela 2 apresenta os valores mínimo, médio e máximo obtidos para os parâmetros físicos das sub-bacias, divididos para as sub-bacias rurais e urbanas da área de estudo. A sub-divisão dos dados nessas classes tomou como referência o coeficiente de impermeabilidade médio de $50 \%$.

Quanto à área das sub-bacias, observa-se que a área variou de 4,36 hectares a uma média de 310 hectares. De acordo com Krebs et al., (2013), que buscou uma metodologia para parametrizar um modelo hidrológico usando o SWMM aplicável a uma área urbana de larga escala, a área para as sub-bacias variou de 6 a 12 hectares. Quanto à largura das maiores sub-bacias, estas se situam majoritariamente na zona rural por haver maior homogeneidade espacial. Niemi et al. (2019), em seu estudo realizado na bacia de Länsi-Pakila, Finlândia, coberta por mais de 50\% com vegetação, no qual se realizou a avaliação da interação entre a forma e o uso do solo da bacia, concluiu que unir sub-bacias com homogeneidade no uso do solo simplifica e mantém a performance nos resultados da modelagem. Quanto ao parâmetro declividade média da superfície das sub-bacias, este variou de suave-ondulado a ondulado.

Na Figura 4, consta a série de precipitação total diária de cada posto ao longo do mês modelado. Dos 11 postos localizados dentro da bacia, apenas 5 possuíam dados de precipitação total diária para o mês de agosto de 1996. O desvio médio percentual da precipitação total mensal desses postos em relação ao posto do Pici foi de $14,9 \%$ para Messejana, $35,2 \%$ para Castelão, $40,3 \%$ para Eusébio, 58,8\% para Maracanaú e 64,3\% para Pacatuba. Quanto à distribuição temporal, pode-se ainda observar na Figura 4 que em todos os postos a precipitação concentrou-se principalmente no início do mês e entre os dias 14 e 19.

A Figura 5 apresenta a curva de reconstituição da maré no porto do Mucuripe para o mês de agosto de 1996 adicionada à foz do rio no modelo. Observa-se que a maré na região é semidiurna, com amplitudes médias na foz do estuário de, aproximadamente, $1,5 \mathrm{~m}$ na sizígia e $0,5 \mathrm{~m}$ na quadratura, caracterizando um estuário de micromaré.

Os resultados das vazões medidas e modeladas, na Seção Barraca, usadas para calibração do modelo são apresentados na Figura 6. Pode-se observar que a seção apresenta uma oscilação completa de maré, havendo, porém, uma relativa defasagem temporal entre a vazão modelada, a medida e a curva da maré. Nicolite et al. (2009) relatam que as marés oceânicas podem sofrer

Tabela 2 - Caracterização dos parâmetros área de drenagem, largura característica e declividade média das 173 sub-bacias delimitadas.

\begin{tabular}{|c|c|c|c|c|c|c|}
\hline \multirow{2}{*}{$\begin{array}{l}\text { Parâmetros das } \\
\text { sub-bacias }\end{array}$} & \multicolumn{3}{|c|}{ Sub-bacias rurais } & \multicolumn{3}{|c|}{ Sub-bacias urbanas } \\
\hline & Mínimo & Médio & Máximo & Mínimo & Médio & Máximo \\
\hline A - ha & 4,360 & 310,677 & $1.452,130$ & 0,460 & 300,678 & $1.489,270$ \\
\hline$W-m$ & 209,200 & $1.632,237$ & $3.810,900$ & 68,300 & 1572,494 & $3.859,300$ \\
\hline $\mathrm{D}(\%)$ & 2,100 & 4,984 & 20,700 & 0,000 & 2,903 & 4,200 \\
\hline N_Perv & 0,115 & 0,142 & 0,150 & 0,014 & 0,100 & 0,150 \\
\hline N_Imperv & 0,025 & 0,070 & 0,150 & 0,005 & 0,017 & 0,025 \\
\hline S_Perv- mm & 4,501 & 4,933 & 5,080 & 1,905 & 4,032 & 5,080 \\
\hline S_Imperv - mm & 2,186 & 3,298 & 5,080 & 1,905 & 2,070 & 2,345 \\
\hline
\end{tabular}

A: área de drenagem; W: largura característica; D: declividade média; N_Perv: coeficiente de rugosidade para a área permeável; N_Imperv: coeficiente de rugosidade para a área impermeável; S_Perv: armazenamento para a área permeável; S_Imperv: armazenamento para a área impermeável.

Fonte: elaboração própria. 
modificação na fase e distorções de suas amplitudes ao progredirem para águas rasas e ambientes restritos como estuários, onde essas alterações podem ser devidas a fatores como atrito com o fundo, compressão das margens ou a profundidade do canal estuarino.

Ribeiro (2005), ao comparar os resultados de modelos hidráulicos e hidrodinâmicos no estuário do rio Cocó, identificou uma defasagem existente entre diversas seções ao longo do rio, aspecto que ressalta o processo de evolução da maré ao longo do estuário. Assim, pode-se dizer que o SWMM conseguiu

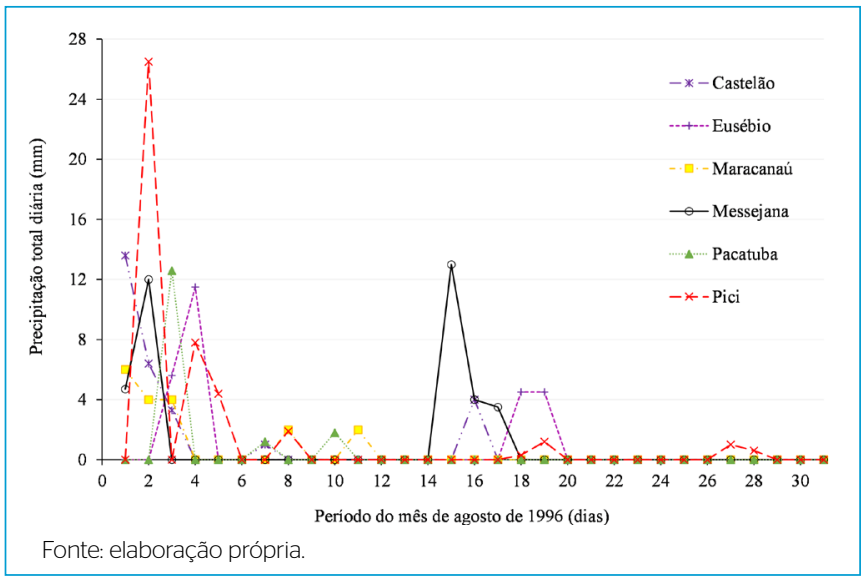

Figura 4 - Precipitação acumulada diária nos postos pluviométricos na bacia e no posto do Pici.

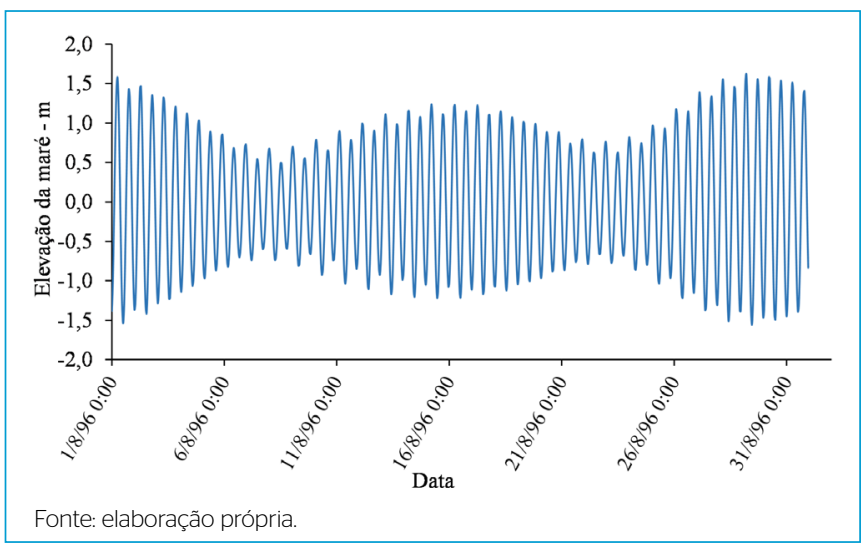

Figura 5 - Variação do nível da maré reconstruída a partir das constantes de maré do marégrafo do Porto do Mucuripe, Fortaleza, Ceará, Brasil.

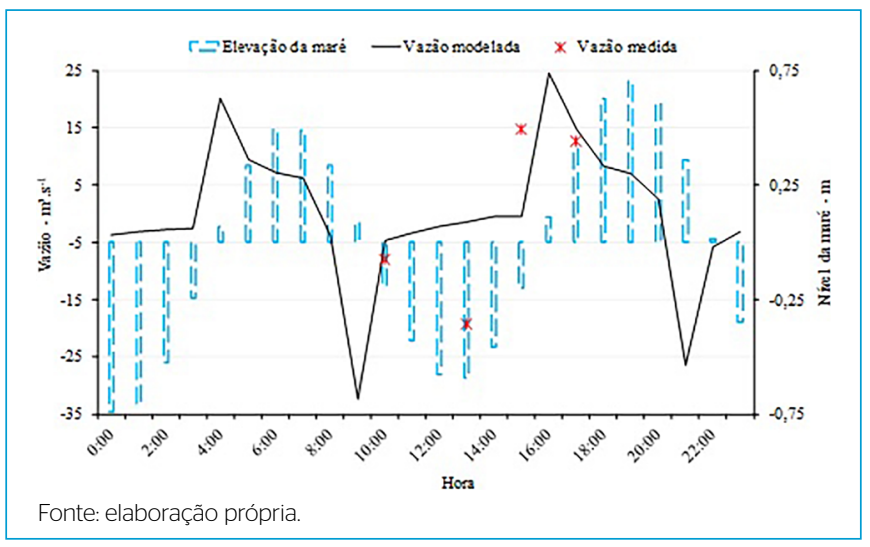

Figura 6 - Vazões medida e modelada na seção calibrada. descrever satisfatoriamente a influência marinha na seção. Obteve-se um coeficiente de Nash-Sutcliffe de 0,5 para a Seção Barraca.

A Seção Árvore, também localizada na região sob influência marinha e com a presença de transientes hidráulicos, foi usada para a validação dos resultados do modelo calibrado. As vazões foram medidas em três momentos do dia 8 de agosto de 1996. A Figura 7 apresenta as vazões medidas e modeladas, junto à curva de maré adicionada ao exutório da bacia para essa seção. As vazões modeladas variaram de $-2,26$ a $4,24 \mathrm{~m}^{3} \cdot \mathrm{s}^{-1}$ enquanto as vazões medidas variaram de $-4,78$ a $5,42 \mathrm{~m}^{3} \cdot \mathrm{s}^{-1}$.

Observa-se na Figura 7 a convergência da forma da vazão modelada em relação às medidas, embora o próprio valor das vazões medidas seja relativamente superior aos valores modelados. O coeficiente de Nash-Sutcliffe obtido para essa seção foi de 0,57, evidenciando, similarmente à Seção Barraca, uma boa aproximação do modelo em reproduzir as vazões de campo.

Os resultados da simulação mostraram ainda que o regime de escoamento na seção validada é majoritariamente influenciado pelo nível da maré, aspecto observado por Leitão (2018) ao realizar a modelagem hidrodinâmica do rio Cocó no HEC-RAS, concluindo que a influência marinha se estende até $11 \mathrm{~km}$ a partir da foz. Os efeitos da precipitação, porém, são perceptíveis, conforme mostra a Figura 8, ao gerarem uma mudança no hidrograma de vazão no trecho, produzindo um fluxo preferencialmente positivo, ou seja, para a foz do rio advinda da descarga fluvial da bacia.

As vazões de descarga da bacia, mais intensas e perceptíveis na Figura 8 entre 80 e 100 horas de simulação, chegaram a 4,33 $\mathrm{m}^{3} \cdot \mathrm{s}^{-1}$, com média de $2,35 \mathrm{~m}^{3} \cdot \mathrm{s}^{-1}$. Molisani, Cruz e Maia (2006) estimaram a descarga fluvial média da bacia do rio Cocó ao estuário em $3 \mathrm{~m}^{3} \cdot \mathrm{s}^{-1}$ durante o período seco, apresentando assim um desvio médio de $22 \%$ em comparação à descarga fluvial média obtida neste

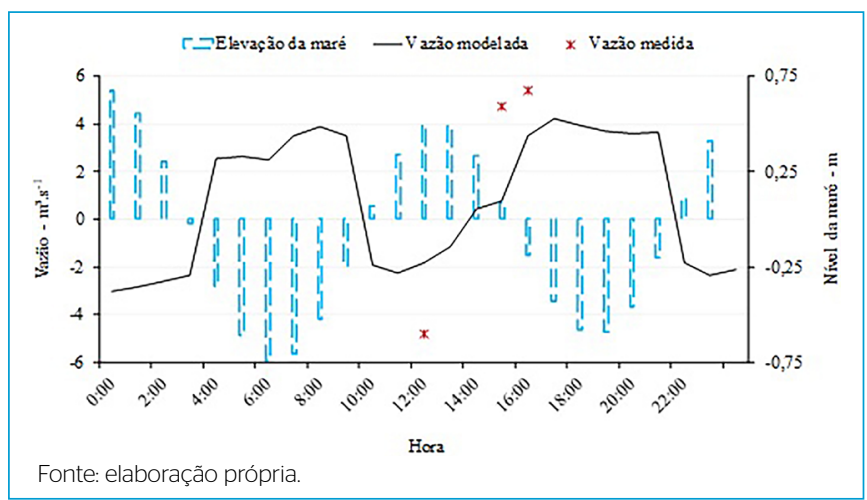

Figura 7 - Vazões medida e modelada na seção validada.

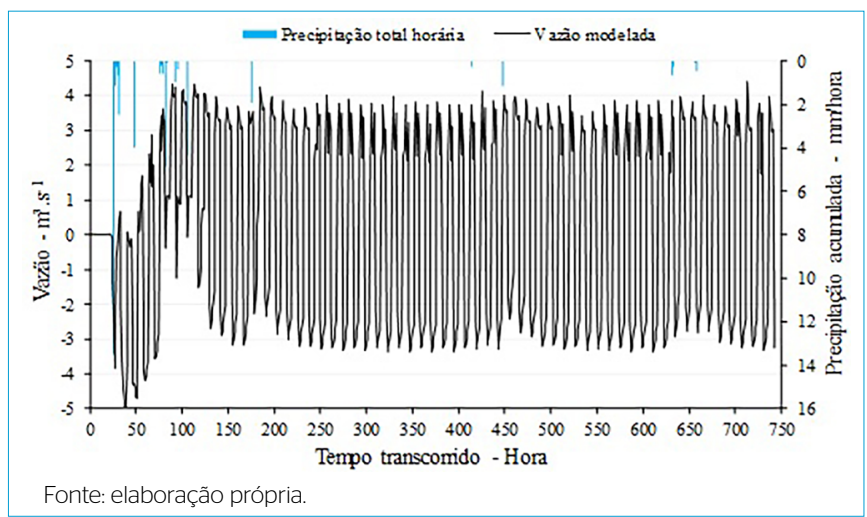

Figura 8 - Vazão modelada mensal e precipitação para a Seção Árvore. 
trabalho. Ressalta-se, assim, que o processo de transformação chuva-vazão utilizando o SWMM é capaz de reproduzir a descarga fluvial de bacias hidrográficas heterogêneas com significativo êxito diante dos demais modelos já utilizados.

Obteve-se também a vazão total afluente ao reservatório Gavião, unidade de armazenamento adicionada ao modelo, para o período modelado, conforme apresenta a Figura 9. Das 84 sub-bacias discretizadas no modelo com percentual de impermeabilidade inferior a 0,5, 18 drenam para esse reservatório, aproximadamente $21 \%$ das sub-bacias rurais do sistema.

Observa-se na Figura 9 as maiores vazões no início do mês, em resposta direta às precipitações ocorridas, com pico de $6,75 \mathrm{~m}^{3} . \mathrm{s}^{-1}$, e os demais períodos sem vazão em quase todo o tempo. A vazão média mensal modelada afluente ao reservatório foi de $0,33 \mathrm{~m}^{3} \cdot \mathrm{s}^{-1}$. Teixeira (2003), ao utilizar o Modelo Hidrológico Auto-Calibrável (MODHAC) para gerar séries de afluência mensal pseudo-históricas para reservatório Gavião de 1912 a 1996, obteve para o mês de agosto de 1996 a afluência média mensal de $0,30 \mathrm{~m}^{3} \cdot \mathrm{s}^{-1}$. Em relação ao presente trabalho, o desvio médio percentual obtido entre os dois modelos foi de, aproximadamente, $10 \%$. Assim, a aproximação dos resultados entre os modelos reforça a aplicabilidade da metodologia e do modelo utilizados neste trabalho também em áreas de transição urbano-rural para previsão de vazões afluentes.

O resultado das vazões medidas e modeladas para a Seção 1, localizada na zona rural da bacia sob aporte permanente da vazão de descarga dos filtros da Estação de Tratamento de Água Gavião, é apresentado na Figura 10, com a vazão média liberada para o sistema de drenagem. A vazão constante existente

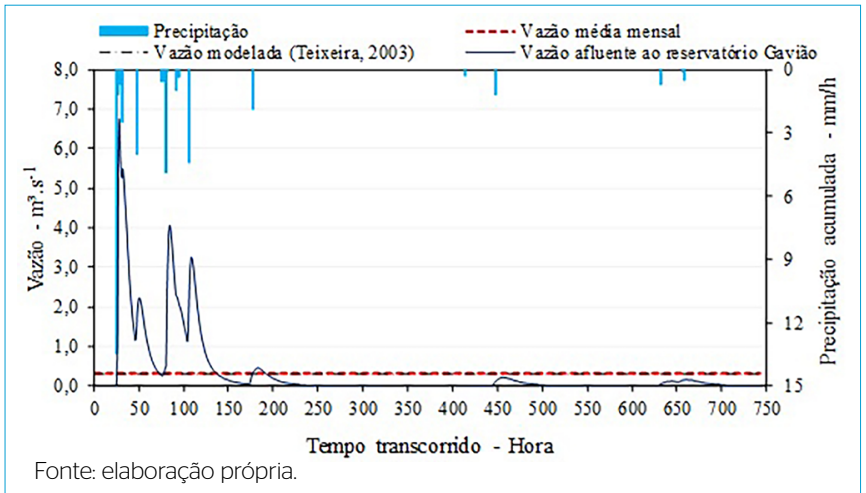

Figura 9 - Precipitação e vazão modelada mensal afluente ao reservatório Gavião.

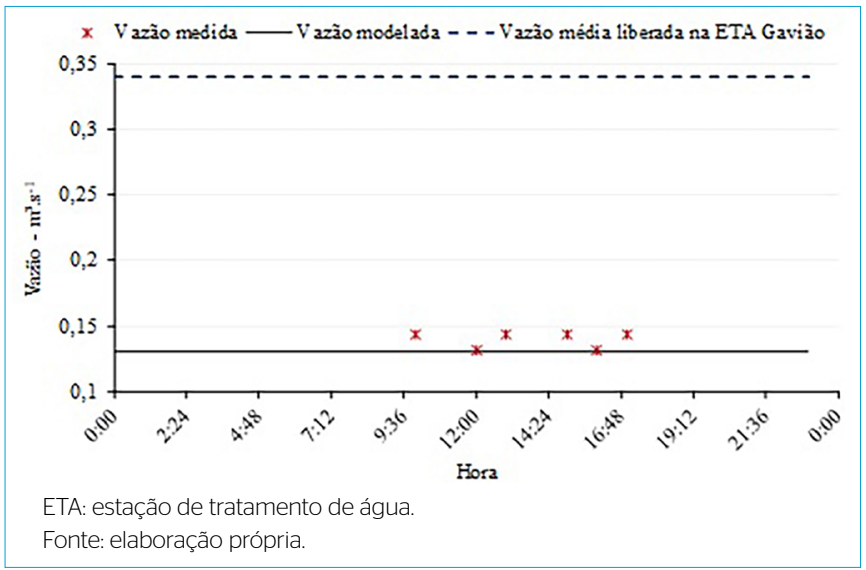

Figura 10 - Vazões medida e modelada na Seção 1 a jusante da Estação de Tratamento de Água Gavião. no trecho deve-se principalmente ao fato de a seção localizar-se muito próximo à estação de tratamento, a qual lança permanentemente uma vazão nesse trecho. Ademais, a água que escoa por esse trecho advém em maior volume quando o reservatório Gavião verte, aspecto que não ocorreu durante o período simulado. Nóbrega (1998) mediu no respectivo trecho vazões aproximadamente constantes que variaram de $0,131 \mathrm{a} 0,143 \mathrm{~m}^{3} \cdot \mathrm{s}^{-1}$. O valor modelado foi o valor constante de $0,130 \mathrm{~m}^{3} \cdot \mathrm{s}^{-1}$, apresentando desvio médio de $8,6 \%$ em relação às vazões medidas.

\section{CONCLUSÕES}

O presente trabalho apresentou os resultados da modelagem hidrológico-hidráulica realizada com o SWMM, integrado a ferramentas SIG, para a macrodrenagem de uma grande bacia situada em área de transição urbano-rural com influência marinha nos trechos da foz. Para as simulações, realizou-se a discretização da área em estudo em sub-bacias, delimitou-se o sistema de macrodrenagem existente, construiu-se um mapa de uso e ocupação do solo, estimaram-se os parâmetros físicos e espaciais de cada sub-bacia e trecho da drenagem, e reconstituiu-se uma curva de maré para o exutório da bacia a partir do método harmônico.

A modelagem realizada para o período de um mês mostrou que o SWMM conseguiu descrever satisfatoriamente a influência marítima nos trechos da região estuarina da bacia e que houve boa convergência entre as vazões medidas e modeladas com coeficiente de Nash-Sutcliffe de 0,5 para a seção calibrada e 0,57 para a seção validada. Ao trecho validado na zona rural da bacia, imediatamente a jusante do reservatório Gavião e sob regime de vazão aproximadamente constante, obteve-se um desvio médio entre as vazões medidas e modeladas de 8,6\%.

Ademais, a vazão modelada de descarga fluvial da bacia ao estuário foi de $2,35 \mathrm{~m}^{3} . \mathrm{s}^{-1}$, em média, apresentando um desvio aproximado de $22 \% \mathrm{em}$ comparação à descarga fluvial obtida na literatura. Quanto à vazão mensal produzida nas sub-bacias rurais do sistema afluente ao reservatório Gavião, obteve-se o valor médio mensal de $0,33 \mathrm{~m}^{3} \cdot \mathrm{s}^{-1}$, que apresentou desvio médio percentual aproximado de $10 \%$ em relação à vazão produzida em trabalhos anteriores utilizando o modelo hidrológico MODHAC. Dessa maneira, assevera-se que o software e a metodologia avaliados e validados neste trabalho apresentam-se como uma nova abordagem para reprodução do processo de transformação chuva-vazão em bacias hidrográficas complexas.

Destaca-se também a considerável relevância da metodologia apresentada neste trabalho para a caracterização física e espacial da bacia e dos elementos de drenagem, bem como o método para reconstituição da curva de maré utilizada para melhorar a aproximação obtida entre os resultados modelados e os medidos. Em síntese, os resultados obtidos indicam que o SWMM integrado a ferramentas SIG pode ser utilizado para a modelagem hidrológico-hidráulica e para a reprodução de vazões de grandes bacias heterogêneas e ainda sob influência de maré, apresentando-se como potencial ferramenta para auxiliar na gestão integrada de águas rurais, urbanas e costeiras.

\section{CONTRIBUIÇÕES DOS AUTORES}

Rocha, M. J. D.: Conceituação, Curadoria de Dados, Análise Formal, Metodologia, Escrita - Primeira Redação. Pereira, S. P.: Conceituação, Metodologia, Escrita Revisão e Edição. Lima Neto, I. E.: Conceituação, Obtenção de Financiamento, Metodologia, Supervisão, Escrita - Revisão e Edição. 


\section{REFERÊNCIAS}

BABOVIC, F.; MIJIC, A.; MADANI, K. Decision making under deep uncertainty for adapting urban drainage systems to change. Urban Water Journal, v. 15, n. 6, p. 552-560, 2018. https://doi.org/10.1080/1573062X.2018.1529803

BARCO, J.; WONG, K.M.; STENSTROM, M.K. Automatic Calibration of the U.S. EPA SWMM Model for a Large Urban Catchment. Journal of Hydraulic Engineering, v. 134, n. 4, p. 466-474, 2008. https://doi.org/10.1061/ (ASCE)0733-9429(2008)134:4(466)

BATISTA, J.A.N.; BOLDRIN, A.J. Avaliação do desempenho hidráulico de um sistema de drenagem de águas pluviais urbanas. Engenharia Sanitária e Ambiental, v. 23, n. 2, p. 263-273, 2018. https://doi.org/10.1590/s141341522018170663

BEZERRA, J.A.; SILVA, C.N.M. Entre o rural e o urbano interiorizado. Mercator, v. 17, e17019, 2018. https://doi.org/10.4215/rm2018.e17019

BLÖSCHL, G.; BARDIN, S.A.; BONELL, M.; DORNINGER, M.; GOODRICH, D.; GUTKNECHT, D.; MATAMOROS, D.; MERZ, B.; SHAND, P.; SZOLGAY, J. At what scales do climate variability and land cover change impact on flooding and low flows? Hydrological Processes, v. 21, n. 9, p. 1241-1247, 2007. https://doi. org/10.1002/hyp.6669

BOSCH, J.M.; HEWLETT, J.D. A review of catchment experiments to determine the effect of vegetation changes on water yield and evapotranspiration. Journal of Hydrology, v. 55, n. 1-4, p. 3-23, 1982. https:// doi.org/10.1016/0022-1694(82)90117-2

CARDOSO, M.S.S.; MULLER, S.C.; DUARTE, A.A.A.M.; LIMA, J.J.F. Ações de regularização fundiária e de mensuração das desconformidades urbanas: o caso das terras da União sob a tutela da Universidade Federal do Pará na cidade de Belém (PA). URBE, Revista Brasileira de Gestão Urbana, v. 6, n. 3 , p. 307-322, 2014. https://doi.org/10.7213/urbe.06.003.ACO3

CAMPOS, J.N.B.; RABELO, U.P.; LIMA NETO, I.E. The Bell-Shaped Unit Hydrograph for Overland Planes. Journal of Irrigation and Drainage Engineering, v. 146, n. 5, 06020001, 2020. https://doi.org/10.1061/(ASCE) IR.1943-4774.0001465

CHOW, V.T. Open-channel hydraulics. Nova York: McGraw-Hill Book Company, 1973.

Companhia de Gestão dos Recursos Hídricos (COGERH). Revisão do plano de gerenciamento das águas da bacia metropolitana e elaboração dos planos de gerenciamento das águas das bacias do Litoral, Acaraú e Coreaú, no estado do Ceará. Relatório de tarefas. Fortaleza: COGERH, 2010.

FORMIGA, K.T; CARVALHO, M.; SILVA, K.A.; SOARES, A.K. Calibração do Storm Water Management Model (SWMM) utilizando algoritmos evolucionários multiobjetivo. Engenharia Sanitária e Ambiental, v. 21, n. 4, p. 697-707, 2016. https://doi.org/10.1590/s1413-41522016131862

FUNDAÇÃO CEARENSE DE METEOROLOGIA E RECURSOS HÍDRICOS (FUNCEME). Calendário de Chuvas do estado de Ceará. Ceará: FUNCEME, 2019. Disponível em: http://www.funceme.br/app/calendario/. Acesso em: 25 maio 2019

GIRÃO, L.F.O.; SIMÕES, N.E.C.; MARQUES, J.A.A.S.; LEITÃO, J.P.C.; PINA, R.D. Modelação hidráulica e de qualidade da água dos sistemas de drenagem em meios urbanos. Engenharia Sanitária e Ambiental, v. 22, n. 2, p. 351-360, 2017. https://doi.org/10.1590/s1413-41522016161318
GIRONÁS, J: ROESNER, L.A.:DAVIS, J.Storm watermanagementmodel:applications manual. Fort Collins: U.S. Environmental Protection Agency, Department of Civil and Environmental Engineering. Colorado State University, 2009.

Kong, F.; Ban, Y.; YIN, H.; James, P.e.; Dronova, I. Modeling stormwater management at the city district level in response to changes in land use and low impact development. Environmental Modelling and Software, v. 95, p. 132-142, 2017. https://doi.org/10.1016/j.envsoft.2017.06.021

KREBS, G.; KOKKONEN, T.; VALTANEN, M.; KOIVUSALO, H.; SETÄLÄ, H. A high resolution application of a stormwater management model (SWMM) using genetic parameter optimization. Urban Water Journal, v. 10, n. 6, p. 394-410, 2013. https://doi.org/10.1080/1573062X.2012.739631

LEI, C.; ZHU, L. Spatio-temporal variability of land use/land cover change (LULCC) within the Huron River: Effects on stream flows. Climate Risk Management, v. 19, p. 35-47, 2018. https://doi.org/10.1016/j.crm.2017.09.002

LEITÃO, F.T.P. Modelagem hidrodinâmica 1D, 1D/2D e 2D do efeito de maré no rio Cocó. 139f. Dissertação (Mestrado em Hidráulica e Saneamento Ambiental) - Departamento de Engenharia e Hidráulica Ambiental, Universidade Federal do Ceará, Fortaleza, 2018.

MAKSIMOVIC, C.; PRODANOVIĆ, D.; BOONYA-AROONNET, S.; LEITÃO, J.P.; DJORDJEIVC, S.; ALLITT, R. Overland flow and pathway analysis for modelling of urban pluvial flooding. Journal of Hydraulic Research, v. 47, n. 4, p. 512-523, 2009. https://doi.org/10.1080/00221686.2009.9522027

MESQUITA, J. B. F.; PEREIRA, S. P.; LIMA NETO, I. E. Modelagem da drenagem urbana e avaliação das cargas bacteriológicas na Vertente Marítima de Fortaleza, Ceará. Engenharia Sanitária e Ambiental, v. 25, n. 1, p. 205-216, 2020. https://doi.org/10.1590/s1413-41522020189161

MIRANDA, H.; GOMES-JÚNIOR, E. Urbanização reflexa: A emergência de arranjos urbanos intermediários no Brasil pós-1990. Eure, v. 43, n. 130, p. 207-234, 2017. https://doi.org/10.4067/s0250-71612017000300207

MOLISANI, M.M.; CRUZ, A.L.V.; MAIA, L.P. Estimativa da descarga fluvial para os estuários do Estado do Ceará, Brasil. Arquivos de Ciências do Mar, v. 39, n. 1-2, p. 53-60, 2006. https://doi.org/10.32360/acmar.v39i1-2.6173

NGUYEN, P:; THORSTENSEN, A.; SOROOSHIAN, S.; HSU, K:; AGHAKOUCHAK, A. SANDERS, B:; KOREN, V:; CUI, Z; SMITH, M. A high resolution coupled hydrologichydraulic model (HiResFlood-UCl) for flash flood modeling. Journal of Hydrology, v. 541, parte A, p. 401-420, 2016. https://doi.org/10.1016/j.jhydrol.2015.10.047

NICOLITE, M.; TRUCCOLO, E.C.; SCHETTINI, C.A.F.; CARVALHO, C.E.V. Oscilação do nível de água e a co-oscilação da maré astronômica no baixo estuário do rio Paraíba do Sul, RJ. Revista Brasileira de Geofísica, v. 27, n. 2, p. 225-239, 2009. https://doi.org/10.1590/S0102261X2009000200006

NIEMI, T.J.; KOKKONEN, T.; SILLANPÄÄ, N.; SETÄLÄ, H.; KOIVUSALO, H. Automated Urban Rainfall-Runoff Model Generation with Detailed Land Cover and Flow Routing. Journal of Hydrologic Engineering, v. 24, n. 5 , 04019011, 2019. https://doi.org/10.1061/(ASCE)HE.1943-5584.0001784

NÓBREGA, M.T. Simulação do comportamento dos transientes hidráulicos na calha do rio Cocó. 152f. Dissertação (Mestrado em Hidráulica e Saneamento Ambiental) - Departamento de Engenharia e Hidráulica Ambiental, Universidade Federal do Ceará, Fortaleza, 1998. 
PEREIRA, S.P.; ROSMAN, P.C.; ALVAREZ, C.; SCHETINI, C.A.; SOUZA, R.O.; VIEIRA, R.H. Modeling of coastal water contamination in Fortaleza (Northeastern Brazil) (2015). Water Science and Technology, v. 72, n. 6, p. 928-936, 2015. https://doi.org/10.2166/wst.2015.292

RIBEIRO, R.S. Intercomparação de modelos hidrodinâmico e hidráulico no estudo de rio estuarino. 100f. Dissertação (Mestrado em Hidráulica e Saneamento Ambiental) - Departamento de Engenharia e Hidráulica Ambiental, Universidade Federal do Ceará, Fortaleza, 2005.

RODRIGUEZ, D.A.; TOMASELLA, J.; LINHARES, C. Is the forest conversion to pasture affecting the hydrological response of Amazonian catchments? Signals in the Ji-Paraná Basin. Hydrological Processes, v. 24, n. 10, p. 1254 1269, 2010. https://doi.org/10.1002/hyp.7586
SANDWELL, D.T.; MYER, D.; MELLORS, R.; SHIMADA, M.; BROOKS, B.; FOSTER, J. Accuracy and resolution of ALOS interferometry: Vector deformation maps of the father's day intrusion at Kilauea. IEEE Transactions on Geoscience and Remote Sensing, v. 46, n. 11, p. 3524-3534, 2008. https://doi. org/10.1109/TGRS.2008.2000634

TEIXEIRA, F.L. Modelagem de séries fluviométricas para o Semi-Arido brasileiro via redes neurais artificias. 165f. Dissertação (Mestrado em Hidráulica e Saneamento) - Escola de Engenharia de São Carlos, Universidade de São Paulo, São Carlos, 2003.

VINAGRE, M.V.A.; LIMA, A.C.M.; LIMA JÚNIOR, D.L. Estudo do comportamento hidráulico da Bacia do Paracuri em Belém (PA) utilizando o programa Storm Water Management Model. Engenharia Sanitária e Ambiental, v. 20, n. 3, p. 361-368, 2015. https://doi.org/10.1590/S1413-41522015020000106515 